\title{
A new method for the recovery and evidential comparison of footwear impressions using 3D structured light scanning
}

\begin{abstract}
Footwear impressions are one of the most common forms of evidence to be found at a crime scene, and can potentially offer the investigator a wealth of intelligence. Our aim is to highlight a new and improved technique for the recovery of footwear impressions, using three-dimensional structured light scanning. Results from this preliminary study demonstrate that this new approach is non-destructive, safe to use and is fast, reliable and accurate. Further, since this is a digital method, there is also the option of digital comparison between items of footwear and footwear impressions, and an increased ability to share recovered footwear impressions between forensic staff thus speeding up the investigation.
\end{abstract}

\section{Introduction}

Footwear marks and impressions are a common form of evidence left at a crime scene (Srihari, 2011). Although the majority of casework will involve two-dimensional recording methods, the potential of using three dimensions is great. Traditional methods used to recover three-dimensional (3D) footwear impressions involve taking two-dimensional (2D) colour photographs (Blitzer et al., 2015; Kuzminsky and Gardiner 2012), and creating a physical cast off the impression. These photographs can capture unique features of the impression but they do not adequately provide metric depth measurements of these features (Gamage 2013). Further, the quality of the photograph, the type of camera film used, and the presence of shadows cast across the impression can reduce their usefulness (Blitzer et al., 2015). A physical cast, in contrast, can overcome these issues and be an effective supplement to the analysis of these characteristics.

Nonetheless, there are some considerations that need to be taken into account before producing a cast, such as the need to ensure the correct technique for making the casting material and then subsequent produce the correct consistency of casting material, and the fact that evidence is often destroyed during the actual casting process (Abbott, 1964; Svensson and Wendell, 1981). It has been noted 
generally that there is little substantive research investigating the most appropriate practice in the field (Battiest et al., 2016). Some substrates such as sand and snow can prove to be particularly problematic substrates to recover impressions from (Petraco et al., 2016), since sand is very fragile and snow melts during the exothermic reaction of the casting material. One approach to this has been to spray the impression with a fixative to highlight the detail before the dental stone can be poured in (Battiest et al., 2016; Houck, 2015), while another has been to use foam blocks (Petraco et al., 2016). Both approaches demand physical intervention with the impressions which ultimately reinforces the notion that there is only one chance to recover an impression - regardless of how significant it is to the investigation.

Due to these factors, practitioners have been looking to alternative methods of recovering footwear impression evidence. Studies have been conducted into the use of 3D laser scanners (e.g.: Buck et al. 2007; Komar et al. 2012; Gamage et al. 2013), and other techniques of 3D imaging (e.g.: Andalo et al., 2011). Digital and 3D scanning approaches offer several potential benefits to practitioners, including greater efficiency in contexts with multiple overlapping footwear impressions since once the scan data has been acquired, it is then possible to segment the image to highlight the individual footwear impressions. Although these digital laser scanning techniques have shown promise, they do come with their own sets of caveats. These have included the questionable accuracy of measurement, the missing data, incomplete 3D models, and unacceptable levels of noise when used on dark or reflective/metallic surfaces (Buck et al. 2007). This last point is a function of beam absorption or reflectance on these surfaces (Barbero and Ureta 2011).

Nevertheless, non-contact scanning seems to offer great potential due to its nondestructive nature. Therefore, this research introduces the use of an alternative method - that of structured light scanning. Structured light scanners are already being used successfully in other areas of research, such as anthropology and architecture (see for example, Betts et al., 2011; Errickson et al., 2014; Niven et al., 2009; McPherron et al., 2009; Stančić et al., 2013). In addition to collecting 3D morphological data, structured light scanners capture colour information during the acquisition process. In contrast, laser scanners often require colour to be mapped onto the 3D data during the subsequent processing stage (Errickson et al., 2017). 
Other potential advantages of structured light scanning include cheaper equipment and high resolution combined with high efficiency. Structured light scanners like the one used in this research are also portable.

This research project had two aims, which were explored using a controlled, laboratory-based set of experiments. The first is to assess the ability of structured light scanning to recover footwear impressions from different substrates. The second was to determine whether the 3D scan of the footwear impressions and the footwear outsoles could be compared using readily-available computer software. Although an assessment of the accuracy of this method for actual use in the courts was not an aim of this study.

\section{Method}

A PicoScan (4D Dynamics, Belgium) 3D structured light scanner, comprising a Cannon EOS $1100 \mathrm{D}$ camera and a vertically mounted Pico projector connected to a laptop, was used in this study. The PicoScan was chosen as it has been shown to be effective in recording and supporting the analysis of material of forensic interest and best practice guidance has been published (Errickson et al., 2015; 2017). The scanner must be calibrated using a geometrical calibration. In order to do this, intrinsic, extrinsic and radiometric properties have to be determined. This is a straightforward process that can be achieved in the laboratory or in the field. A checkerboard is used during the calibration process. The camera's optical focal length and the intensity of the projector will determine the size of the checkerboard to be used. During this study a checkered pattern of $21 \times 15$ squares of $11 \mathrm{~mm}^{2}$ was used. An important aspect of recovering forensic evidence is the accuracy in which it is obtained (Niven et al. 2009), and this method of calibration has been demonstrated to provide a point accuracy of $0.1 \mathrm{~mm}$ (Errickson et al. 2014).

Once the scanner has been successfully calibrated the footwear impression to be scanned can be put into the view of the camera. It is important that the projector and the camera's lens are not moved following the calibration procedure because it can affect the accuracy of the results. The mounted projector emits a known pattern of light resulting from this calibration process onto the footwear impression. The presence of the 3D impression deforms the pattern of light, which the camera then 
records and stores. The scanner must then be moved around the footwear impression (or vice versa) to ensure that the impression is imaged from all angles. After the acquisition of the scan data, the software 'Process' allowed the researcher to stitch together all of the individual scans taken from each angle to create one final water-tight 3D model. Subsequently, noise (unwanted data caused by the reflection of light) that was created during the scanning process was removed. The final model was exported in a number of different standard file formats, including .ply, .obj and .stl. As the method is non-contact if a problem occurred during the scanning process, the process could simply be repeated.

Following export of the final models (which averaged a relatively small $\sim 50 \mathrm{~kb}$ ), the files were uploaded into CloudCompare (http://www.danielgm.net/cc/) and MeshLab (GPLsoftware 2015; CNR 2014) for measurement and analysis. These software packages were chosen because they are freely available to download and therefore are available to all practitioners, regardless of budget. There are many functions within CloudCompare that can be used to conduct analyses of the 3D scans, including a measurement tool and an alignment function (which can be used to compare a footwear impression with the relevant scanned outsole; Figure 1). Once the alignment function has been utilised, the user can then use the Iterative Closest Point (ICP) tool to minimize the differences between two point clouds. Once alignment has been achieved, it is then possible to compute the cloud-to-cloud distances between the two models (Figure 1). The results from this process can be displayed as a scalar field (Figure 2) with the results given as the standard deviation and the mean of the distances. The advantage of this approach is that a statistical value is ascribed to the closeness of the match. Finally, the digital model was used to create a rapid prototype of a scanned impression in order to assess its potential to replace traditional casts.

Seven items of footwear, selected to represent a range of designs were used to create footwear impressions in trays of sand and soil. Both the footwear impressions and the outsole used to create that impression were scanned using the structured light scanner. Table 1 presents the details of the footwear used. Measurements were taken from the scanned footwear outsole using the MeshLab software, and measurements of the actual items of footwear were taken using a digital caliper with 
a \pm accuracy of $1 \mathrm{~mm}$. Casts were made of the footwear impressions following standard and recommended methods.

\section{Results}

Figures 3-9 show scanned images obtained from sand, soil and the scanned image of the footwear outsole that made the impressions. Table 2 presents the approach to comparing the methods of measurements undertaken on the footwear (Table 1).

The item of footwear and the impression of interest were not always flat when the images are overlaid (Figure 10), therefore the scan of the shoe was segmented into two or more sections (Figure 11 demonstrates where the show has been segmented into the heel and forefoot section). The areas for segmentation depended on the item of footwear in question, the type of impression, and fundamentally how the individual walked in the substrate to make the impression of interest. For example, according to Bodziak (2000), there are two types of impressions. First, an even impression is where the item of footwear has made contact with a given surface in one downward level movement; in doing so there will be very little distortion to the impression that is created. The second type of impression is where the heel strikes the ground and in doing so pushes some of the substrate forward. The item of footwear will then roll over the displaced substrate before pushing off with the front part of the footwear. When deciding where to segment the item of footwear it is best to consider how the impression has been made so that the segmenting is appropriate.

As noted above, a key tool for comparison for traditional footwear impression examination is the physical cast which can be studied, analysed and used in comparisons. Figure 12 shows a visual depiction of a 3D print, a cast and an image of the outsole that left the footwear impression. The outsole pattern was compared in each case. The comparison did not consider fine details such as randomly acquired characteristics. The highlighted area on the 3D print shows a portion of the tread from an item of footwear which cannot be seen on the traditional cast. 


\section{Discussion}

The results presented here demonstrate that 3D structured light scanning offers the forensic and crime scene examiner a new method for the recovery of footwear impressions. The use of the structured light scanner allows the evidence to be collected in a non-destructive manner and at a much faster rate than some traditional methods of photography and casting techniques. Work here has shown that a user would be able to, on average, scan the impression and complete any post processing tasks in approximately 90 minutes. In contrast, the guide produced by the Scientific Working Group for Shoeprint and Tire Tread Evidence (SWGTREAD) suggests that a cast made using dental stone should be left for 48 hours to harden before starting the cleaning process. Bodziak (2000) also states that the cast should be air dried for 48 hours before cleaning. Note however, that any post-processing that is to be done to the $3 \mathrm{D}$ models, such as segmenting the data (as described above), will add time and potentially error to the analysis.

The results demonstrate that the digital models themselves also offer greater flexibility than traditional outputs. Due to the relatively small files sizes it is possible for the images to be easily transferred digitally or linked to databases. It is also possible to view the scans on mobile devices, such as smartphones and tablets. The use of 3D scans offers the user the ability to print the impressions if required, and the digital models can be readily incorporated into animations which can be created for presentation in the court room.

Although it was possible to compute results from CloudCompare using the mesh-tomesh distances in order to perform direct comparisons of the footwear outsole to the footwear impression in the substrate, it is not felt that these are reliable results for comparison work at present. More work is needed to understand the impact of substrate movement while the footwear being lifted out of the sample since this was shown to result in 3D models smaller than the actual footwear. Relatedly, the method described above should be applied to footwear marks in non-soil substrates, such as blood (see for example, McElhone et al., 2016) since comparisons should still be possible. 
To conclude, this study has demonstrated that using a 3D structured light scanner is a viable option when impression evidence needs to be recovered at a crime scene. Future work needs to find a more accurate way of comparing a scanned item of footwear to that of a scanned footwear impression. Work also needs to be undertaken to compare the detail present in the 3D scans of footwear impressions and corresponding casts before recommendations can be made to replace casts. In addition, further work could explore the use of different coloured light sources (and wavelengths) to see if this enhances the information captured. Traditionally, structured light scanners use white light but blue light may also be viable because it has a narrower band width and more is resilient to environmental factors. For example, Friess (2012) states that using blue light will help to overcome some of the issues concerned with examining reflective surfaces, and that it can increase overall scanning resolution. Further, the impact of the weather and variations in ambient light on the scanning process should be investigated. Likewise, the adoption of algorithms for automatic pattern and feature matching, compatibility with national footwear databases, and the application of structured light scanning to other impression evidence require investigation. 


\section{References}

Abbott, J.R. 1964. Footwear Evidence. Charles C Thomas: Springfield IL.

Andalo, F.A., Calakli, F., Taubin, G. and Goldenstein, S. 2011 Accurate 3D footwear impression recovery from photographs. In: Imaging for Crime Detection and Prevention 2011 (ICDP 2011), 4th International Conference.

Barbero, B.R. and Ureta, E.S. 2011. Comparative study of different digitization techniques and their accuracy. Computer-Aided Design 43(2): 188-206.

Battiest, T., Clutter, S.W. and McGill, D. 2016. A Comparison of Various Fixatives for Casting Footwear Impressions in Sand at Crime Scenes. Journal of Forensic Science 61: 782-786.

Betts, M.W., Maschner, H.D.G., Schou, C.D., Schlader, R., Holmes, J., Clement, N., and Smuin, M. 2011. Virtual zooarchaeology: building a web-based reference collection of northern vertebrates for archaeofaunal research and education. Journal of Archaeological Science: 755-762.

Blitzer, H., Hammer, R. and Jacobia, J. 2015. Effect of Photographic Technology on Quality of Examination of Footwear Impressions. Journal of Forensic Identification 65(4): 699-715.

Bodziak, W.J., 2000. Footwear Impression Evidence. CRC Press, Inc.: Boca Raton, USA.

Buck, U., Naether, S., Braun, M., Bolliger, S., Friederich, H., Jackowski, C., Aghayev, E., Christe, A. Vock, P., Dirnhofer, R. and Thali, M.J. 2007. Application of 3D documentation and geometric reconstruction methods in traffic accident analysis: With high resolution surface scanning, radiological MSCT/MRI scanning and real data based animation. Forensic science international 170(1): 20-28.

Errickson, D., Thompson, T.J.U. \& Rankin, B.W.J., 2014. The application of 3D visualization of osteological trauma for the courtroom: A critical review. Journal of Forensic Radiology and Imaging 2(3): 132-137.

Errickson, D., Thompson, T.J.U. and Rankin, B.W.J., 2015. An Optimum Guide for the Reduction of Noise using a Surface Scanner for Digitising Human Osteological Remains. http://guides.archaeologydataservice.ac.uk/g2gp/CS_StructuredLight.

Errickson, D., Grueso, I., Griffith, S.J., Setchell, J.M., Thompson, T.J.U., Thompson, C.E.L., and Gowland, R.L. 2017. Towards a best practice for the use of active noncount surface scanning to record human skeletal remains from archaeological contexts. International Journal of Osteoarchaeology.

Friess, M., 2012. Scratching the surface? The use of surface scanning in physical and paleoanthropology. Journal of Anthropological Sciences 90: 7-31. 
Gamage, R.E., Joshi, A., Zheng, J.Y., and Tuceryan, M. 2013. A high resolution 3D tire and footprint impression acquisition for forensics applications. In: Applications of Computer Vision (WACV), 2013 IEEE Workshop. pp. 317-322

Houck, J.A.S. 2015. Impression Evidence. In: Houck, M. and Siegel, J. (eds.) Fundamentals of Forensic Science ( $3^{\text {rd }}$ Edition). Elsevier: USA. pp. 577-598.

Komar, D.A., Davy-Jow, S. \& Decker, S.J. 2012. The Use of a 3-D Laser Scanner to Document Ephemeral Evidence at Crime Scenes and Postmortem Examinations. Journal of Forensic Sciences 57(1): 188-191.

Kuzminsky, S.C. and Gardiner, M.S. 2012. Three-dimensional laser scanning: potential uses for museum conservation and scientific research. Journal of Archaeological Science 39(8): 2744-2751.

McElhone, R.L., Meakin, G.E., French, J.C., Alexander, T. and Morgan, R.M. 2016. Simulating forensic casework scenarios in experimental studies: The generation of footwear marks in blood. Forensic Science International 264: 34-40.

McPherron, S.P., Gernat, T. and Hublin, J.-J. 2009. Structured light scanning for high-resolution documentation of in situ archaeological finds. Journal of Archaeological Science 36(1): 19-24.

Niven, L., Steele, T.E., Finke, H., Gernat, T. and Hublin, J.-J. 2009. Virtual skeletons: using a structured light scanner to create a $3 \mathrm{D}$ faunal comparative collection. Journal of Archaeological Science 36(9): 2018-2023.

Petraco, N., Sherman, H., Dumitra, A., and Roberts, M. 2016. Casting of 3dimensional footwear prints in snow with foam blocks. Forensic Science International 263: $147-151$.

Srihari, S.N. 2011. Analysis of Footwear Impression Evidence. Final Technical Report, US Department of Justice Award Number 2007-DN-BX-K135.

Stančić, I., Musić, J. and Zanchi, V. 2013. Improved structured light 3D scanner with application to anthropometric parameter estimation. Measurement 46(1): 716-726.

Svensson, A. and Wendell, O. 1981. Techniques of Crime Scene Investigation ( $3^{\text {rd }}$ Edition). Elsevier: New York, USA. 